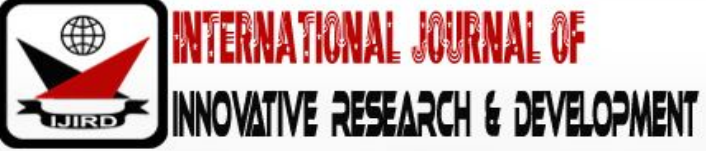

ISSN 2278 - 0211 (Online)

\section{Evaluation of the Nutrient Density and Flavonoid Composition of Pleurotus Ostreatus Cultivated by Substrate Organic Supplementation Techniques}

\begin{tabular}{c}
\hline Dr. P.N. Okoroh \\
Lecturer, Department of Biochemistry, Gregory University, Nigeria \\
Dr. S.C. Onuoha \\
Senior Lecturer, Department of Biochemistry, University of Port Harcourt, Nigeria \\
A.A. Uwakwe \\
Professor, Department of Biochemistry, Gregory University, Nigeria
\end{tabular}

\begin{abstract}
:
Nutrient density and flavonoid composition of Pleurotus ostreatus cultivated by three substrate organic supplementation techniques were investigated using standard methods. The nutrient density values of the macro and trace-minerals revealed that the three samples Avogardo seed supplementation (AVOS) Whole wheat supplementation (WWS) and Soyabean + Avogardo + Wheat + corn(SAWCS) were rich in copper, manganese, zinc, magnesium, iron, potassium and sodium respectively. SAWCS had the highest fibre nutrient density value (193.5), followed by WWS (173.3) and the least was AVOS (156.5) respectively. Vitamin nutrient density values highlighted that the three samples of the mushroom possessed adequate amount of vitamin $B_{2}$, vitamin $B_{1}$ and niacinamide but the value of cyanocobalamin was very low (0.03) in all the samples.Gas chromatographic analysis showed that flavonoid fractions such as catechin, naringinin, rutin, resveratrol, myricetin, morin quercetin and kaempferol were not detected. The results presented in this study showed that substrate organic supplementation method improved the nutritional quality of the mushroom samples and suggest its possible adoption as a technique for enriching mushrooms for food, feed and medicinal formulations.
\end{abstract}

Keywords: Nutrient density, flavonoid, pleurotus ostreatus, organic supplementation technique

\section{Introduction}

For many years' humans have utilized mushrooms as source of food and for the purpose of healing (Maria et al., 2014). Mushrooms have been taken as small medicinal factories that nature has made. They have been revealed to be rich in immense array of new constituents that humans are yet to tap (Guggenhelm et al., 2014). Today, people use solvents to extract chemical substances from mushrooms and trade these substances as supplements in diets, because they believe that these substances have properties that may improve the human immune system and may also block the formation of cancer (Guillamon et al., 2010). Mshigeni and Chang (2000) highlighted that people who are oriented towards health now enjoy new foods which come from mushrooms and these edible substances got from macrofungi make up the foods that are growing at a very rapid rate around the globe.

Human health challenges as a matter of urgent need in developing and developed nation can be addressed by encouraging the people to engage in massive cultivation of macrofungi. Mushroom have been indicated to be a good source of numerous compounds which possess nutritional as well as medicinal benefits (Vaz et al., 2010).

Pleurotus ostreatus is one of the most common mushrooms that local people hunt from the wild. The macrofungi can also be cultivated by people using saw dust as substrate. It has bitter sweet aroma of benzoic aldehyde (Beltran - Garcia et al., 1997). It belongs to the family of mushrooms called Pleurotacea (Kuo, 2005) Its cap is broad with a fan-like shape and the cap spans from $5 \mathrm{~cm}$ to $25 \mathrm{~cm}$. the mushroom has colour ranging from white, gray, tan to dark brown. It is smooth and often lobed; the flesh is white and its thickness varies because of the way its stipe is arranged. The gills may be white or cream in colour, the temperate regions as well as subtropical forests of the globe have the mushroom in numerous quantities.

Pleurotus ostreatus is edible, medicinal and also very common and people grow it in large quantity, trade it as means of generating revenue and for consumption too (Hall, 2010). The mushroom has quality nutritional value, numerous medicinal properties and many other beneficial effects. It has been used as food and as means of treating ailments by numerous people around the globe for many years (Mishra et al., 2013). Pleurotus ostreatus is rich in dietary fibre, sterol, proteins, macro-minerals and trace-rudiments. The mycochemical composition of this macrofungi has made it a special dietary substance for the prevention and treatment of medical conditions associated with high level of cholesterol in the blood (Hossain et al., 2003). People highly cherish the mushroom as valuable food simply because it is low in calories, 
soluble sugars, fat, sodium and cholesterol. It also provides important mineral nutrients such as selenium, potassium, magnesium, copper, calcium, vitamins like riboflavin, niacin, vitamin $\mathrm{D}$, tocopherol, vitamin $\mathrm{C}$, folic acid, vitamin $\mathrm{K}$ and dietary fiber to humans (Maria et al., 2014).

The content, type and concentration of mushroom nutrients are affected by differences in basal substrate used in their cultivation, supplementation technique employed during cultivation, their stage of development, mode of storage, age of harvest, ways of processing as well as the type of solvent and solvent extraction methods (Mattila et al., 2002).

Recently, scientific investigations have focused on the development of methods that may enhance the concentrations of important bioactive components of cultivated mushroom in other to improve their nutritional as well as medicinal values (Feeney et al., 2014).

A scientific evaluation of mushrooms enriched by various supplementation techniques on cultivation may allow the inclusion of macrofungi as part of the food basket of developed and developing nations. Today, humans survive by ultimately engaging in search for food or yet to be known substances which may have nutritional and medicinal value.

In the present study, the researchers aimed at evaluating the nutrient density and flavonoid, composition of Pleurotus ostreatus cultivated by substrate organic supplementation techniques.

\section{Materials and Methods}

\subsection{Collection of Resource Material}

Pleurotus ostreatus fruiting bodies were obtained from the samples cultivated using organic supplementations at the Research Unit Demonstration Farm of the University of Port Harcourt, Rivers State, Nigeria. The samples were dried and stored in tightly sealed containers for the research.

\subsection{Preparation of Pleurotus ostreatus Extract}

The dried macrofungi material was pulverized with a manual grinder and ethanol extraction was carried out. The filtrate was concentrated using a rotary evaporator at a temperature of $55^{\circ} \mathrm{C}$ and the concentrate was subjected to evaporation in a water bath at $55^{\circ} \mathrm{C}$ to obtain a dark paste which was used for flavonoid determination.

\subsection{Determination of Nutrient Density}

The nutrient density values were estimated by using the index of nutritional quality (INQ) rating system (Drewnowski,2005). The calculation is as follows:

Nutrient density $=$

$$
\frac{\text { Amount of Nutrient } / 100 \mathrm{~g} \div \text { RDAfor nutrient }}{\text { Calories } / 100 \mathrm{~g} \text { of food } \div \text { RDCintake }}
$$

Where RDA = Recommended daily allowance;

$\mathrm{RDC}=$ Recommended daily calorie.

\subsection{Evaluation of Flavonoid Fractions In The Samples}

The method of $\mathrm{Zu}$ et al., (2006) was employed to determine flavonoid composition by chromatographic analysis.

\subsection{Statistical Analysis}

Data presented are the means of the result of three replicates with a standard error of less than $5 \%$.

\section{Results}

3.1. The Nutrient Density of Selected Minerals of the Fruiting Bodies of the Three Samples of Pleurotus Ostreatus.

The results of the nutrient density of the selected numerals of the fruiting bodies of the three samples of Pleurotus ostreatus are shown in table 1.Results highlighted the nutrient density of the macro-elements as follows:AVOS (potassium, 74.6), WWS (potassium, 69.7), SAWCS (potassium, 70.2), AVOS (sodium: 3.5), WWS (sodium, 4.8), SAWCS (sodium, 4.1), SAWCS and WWS (calcium, 5.8), AVOS (calcium, 2.14); AVOS (magnesium, 51.5), WWS (magnesium, 48.1), SAWCS (magnesium 47.5); AVOS (copper, 215.9), WWS (copper, 200.9), SAWCS (copper, 226); AVOS (iron, 261); SAWCS (zinc, 198.2) AVOS (Zinc, 179.9), WWS (zinc, 171.9) and AVOS (manganese, 163.2), WWS (manganese, 165.0), SAWCS (manganese, 228). 


\begin{tabular}{|c|c|c|c|c|c|c|c|c|c|c|}
\hline \multicolumn{4}{|c|}{ AVOS } & \multicolumn{4}{c|}{ WWS } & \multicolumn{3}{c|}{ SAWCS } \\
\hline Analyte & RDA & Amount & ND & WHFR & Amt. & ND & WHFR & Amt. & ND & WHFR \\
\hline Sodium & $2400 \mathrm{mg}$ & 117.6 & 3.5 & V.g & 171.7 & 4.8 & Vg & 149.5 & 4.1 & Vg \\
\hline Potassium & $3500 \mathrm{mg}$ & 3654.3 & 74.6 & Exce & 3661.6 & 69.7 & Exce & 3685.9 & 70.1 & Exce \\
\hline Calcium & $13500 \mathrm{mg}$ & 29.92 & 2.14 & Good & 60.72 & 5.8 & Vg & 87.27 & 5.8 & Vg \\
\hline Iron & $18 \mathrm{mg}$ & 58.87 & 233.7 & Exce & 53.35 & 197.6 & Exce & 70.47 & 261 & Exce \\
\hline Magnesium & $420 \mathrm{mg}$ & 287.8 & 51.5 & Exce & 288.5 & 48.1 & Exce & 6.78 & 226 & Exce \\
\hline Copper & $900 \mathrm{mg}$ & 6.05 & 215.9 & Exce & 6.03 & 200.9 & Exce & 6.78 & 226 & Exce \\
\hline Manganese & $2.3 \mathrm{mg}$ & 4.57 & 163.2 & Exxce & 4.93 & 165.0 & Exce & 6.85 & 228 & Exce \\
\hline Zinc & $11 \mathrm{mg}$ & 37.77 & 179.9 & Exce & 6.03 & 171.9 & Exce & 44.59 & 198.2 & Exce \\
\hline
\end{tabular}

Table 1: Nutrient Density of Selected Minerals of the Fruiting Bodies of the Three Samples of Pleurotus Ostreatus

Nutrient density values were obtained based on the index of nutritional quality rating system; AVOS = Avocado supplementation, WWS $=$ Whole wheat supplementation, SAWCS $=$ soya bean + Avocado + Whole wheat + corn supplementation, $\mathrm{ND}=$ nutrient density, $\mathrm{RDA}=$ recommended daily allowance, WHFR $=$ World Health Food Rating: excellent ( $\mathrm{ND} \geq 7.6$ ), very good ( $\mathrm{ND} \geq 3.4$ ) good ( $\mathrm{ND} \geq 1.5$ ), poor $(\mathrm{ND}<1.5)$. Amt = amount, $\mathrm{Vg}=$ very good, Exce=excellent.

\subsection{Nutrient Density of Fibre of the Fruiting Bodies of the Samples}

The results of the fibre nutrient density of the three samples of Pleurotusostreatus are shown in Table 2. Results indicated that AVOS had the highest fibre nutrient density (193.5) followed by WWS (173.3) and AVOS presented the least value of fibre nutrient density (156.5).

\begin{tabular}{|c|c|c|c|c|c|c|c|c|c|c|}
\hline \multicolumn{4}{|c|}{ AVOS } & \multicolumn{4}{c|}{ WWS } & \multicolumn{3}{c|}{ SAWCS } \\
\hline Constituent & RDA & Amount & ND & WHFR & Amt. & ND & WHFR & Amt. & ND & WHFR \\
\hline Fibre & $25 \mathrm{~g}$ & 5.48 & 156.5 & Exce & 6.50 & 173.3 & Exce & 7.26 & 193.5 & Exce \\
\hline
\end{tabular}

\section{Table 2: Nutrient Density of Fibre of the Fruiting Bodies of the Three Samples}

Nutrient density values were obtained based on the index of nutritional quality rating system; AVOS = Avocado supplementation, WWS $=$ Whole wheat supplementation, SAWCS = soya bean + Avocado + Whole wheat + corn supplementation, $\mathrm{ND}=$ nutrient density, $\mathrm{RDA}=$ recommended daily allowance, WHFR $=$ World Health Food Rating: excellent ( $\mathrm{ND} \geq 7.6$ ), very good ( $\mathrm{ND} \geq 3.4$ ) good ( $\mathrm{ND} \geq 1.5$ ), poor $(\mathrm{ND}<1.5)$. Amt = amount, $\mathrm{Vg}=$ very good, Exce=excellent.

\subsection{Nutrient Density of Selected Vitamins of the Fruiting Bodies of the Three Samples of Pleurotus Ostreatus}

The results of the nutrient density of selected vitamins of the three samples of Pleurotus ostreatus are presented in table 3. Riboflavin had the highest nutrient density value in WWS (56.7) followed by SAWCS (10.0) and the least was AVOS (8.54) respectively. The nutrient density value of thiamin in the three samples was in the order: WWS (114.7), SAWCS (68.7) and AVOS (8.54) respectively. Niacinamide presented nutrient density value of 40.7 in SAWCS, 14.7 in WWS and 5.64 in AVOS respectively. All the three samples presented very low nutrient density value for cynocobalamin (0.03).

\begin{tabular}{|c|c|c|c|c|c|c|c|c|c|c|}
\hline \multicolumn{4}{|c|}{ AVOS } & \multicolumn{4}{c|}{ WWS } & \multicolumn{3}{c|}{ SAWCS } \\
\hline Analyte & RDA & Amount & ND & WHFR & Amt. & ND & WHFR & Amt. & ND & WHFR \\
\hline Thiamine & $1.2 \mathrm{~m}$ & 0.90 & 5.30 & Vg & 2.07 & 114.7 & Exce & 1.23 & 63.7 & Exce \\
\hline Riboflavin & $1.3 \mathrm{mg}$ & 1.56 & 8.54 & Exce & 1.11 & 56.7 & Exce & 0.20 & 10.0 & Exce \\
\hline Nacinamide & $16 \mathrm{mg}$ & 12.64 & 5.64 & Vg & 3.47 & 14.7 & Exce & 9.79 & 40.7 & Exce \\
\hline Vit.B $_{12}$ & $2.41 \mathrm{~g}$ & 0.001 & 0.03 & Poor & 0.001 & 0.03 & Poor & 0.001 & 0.03 & Poor \\
\hline
\end{tabular}

Table 3: Nutrient Density of Selected Vitamins of the Fruiting Bodies of the Samples

Nutrient density values were obtained based on the index of nutritional quality rating system; AVOS = Avocado supplementation, WWS $=$ Whole wheat supplementation, SAWCS $=$ soya bean + Avocado + Whole wheat + corn supplementation, $\mathrm{ND}=$ nutrient density, $\mathrm{RDA}=$ recommended daily allowance, WHFR $=$ World Health Food Rating: excellent ( $\mathrm{ND} \geq 7.6$ ), very good ( $\mathrm{ND} \geq 3.4$ ) good ( $\mathrm{ND} \geq 1.5$ ), poor $(\mathrm{ND}<1.5$ ).

\subsection{Flavonoid Composition of the Fruiting Bodies of the Samples of Pleurotus Ostreatus}

The flavonoid composition of the fruiting bodies of the three samples of Pleurotus ostreatus are shown in table 4 . Flavonoids: catechin, naringin, rutin, resveratrol, myricetin, morin, quercetin and kaempferol were not present. 


\begin{tabular}{|c|c|c|c|}
\hline Flavonoids & AVOS & WWS & SAWCS \\
\hline Catechin (CA) & ND & ND & ND \\
\hline Naringenin (NA) & ND & ND & ND \\
\hline Rutin (RU) & ND & ND & ND \\
\hline Resveratrol (RES) & ND & ND & ND \\
\hline Myricetin (MYR) & ND & ND & ND \\
\hline Morin (MOR) & ND & ND & ND \\
\hline Quercetin (QU) & ND & ND & \\
\hline Kaempferol (K) & ND & N
\end{tabular}

Table 4: Flavonoid Composition ( $\mu \mathrm{g} / \mathrm{g}$ dry Weight) of the Samples

Where AVOS =avocado supplementation, WWS = whole wheat supplementation, SAWCS=soy bean, avocado, whole wheat, corn supplementation, ND = not detected

\section{Discussions and Conclusion}

\subsection{Nutrient Density of Selected Minerals}

The nutrient density of any food measures the amount of nutrient in the food relative to its energy content, using the daily reference intake for each nutrient as a reference standard, based on the consumption of 2000kcal energy (Drewnowski,2005).Nutritional density can be employed to identify foods that feature a high concentration of nutrients compared to their calorific value. Generally, this study highlighted that the mushroom samples presented excellent nutrient density for minerals such as potassium, magnesium, copper, zinc and manganese. The variation in the nutrient density of mushrooms could be attributed to species, strain differences as well as their ability to bioaccumulate the minerals and other nutrients into their tissues (Mattila et al., 2002). Climate and season of the year, maturity stage, storage conditions after harvest as well as supplementation methods could affect the mineral nutrient density of mushrooms (Adejumo and Awosanya, 2005). All the samples investigated in this study were rich in potassium. This is in consonant with the studies conducted around the globe (Barros et al., 2008). The value of potassium was much higher than those of sodium. This result is physiologically important to cardiovascular health. The result is comparable to the values obtained by Nakalembe et al., (2015). The values of magnesium in the three samples of Pleurotus ostreatus was higher than that reported by Nakalembeet al., (2015) but low compared to the values in green vegetables, legumes and whole grains (FAO, 1972). Mattila et al., (2002) reported insignificant level of calcium compared to the density estimated in this study. The iron content indicated in this study is lowerthan the value reported by the Food and Nutrition Board (2001) as upper level intake. The bioavailability of iron may be affected by antinutrients such as phytates. Iron is important in the biosynthesis of haemoglobin. Copper is essential in the protection of cardiovascular, skeletal and nervous tissues. This study showed that copper density in the Pleurotus ostreatus samples was high. Studies in Uganda indicated high copper level in wild mushrooms (Kabasa et al., 2006).

\subsection{Fibre Nutrient Density}

The density of fibre in all the macrofungi samples was found to be quite excellent. The values were higher than those reported by Nakalembeet al., (2015). Fibre is important in diets in the control of cholesterol and blood sugar level hence helps to check diseases such as diabetes, obesity and cardiovascular disease.

\subsection{Nutrient Density of Selected Vitamins}

This study revealed appreciable vitamin nutrient density for all the three samples ofPleurotus ostreatus investigated. They were found to possess high levels of vitamin $B_{2}$, vitamin $B_{3}$ and niacinamide. Vitamins are important in our diets in preventing diseases. The study conducted by Nakalembeet al., (2015) highlighted that wild edible mushrooms exhibited a good profile of vitamins such as thiamin, niacin, folic acid, vitamin $\mathrm{C}$ as it was observed also in the studies by Mattilaet al., (2002).

\subsection{Flavonoid Compositions}

Chromatographic evaluation of the flavonoid composition of the samples of Pleurotus ostreatus in this study indicated that flavonoids were not present. The results are in concord with the report of Alicia et al., (2015) who of recent indicated that macrofungi do not possess flavonoids because they lack the enzymes responsible for the synthesis of flavonoids (which are present in the green plants) such as chalcone isomerase and chalcone synthase. According to their report, a scientific analysis was carried out on macrofungi obtained from substrates made up of wastes from onion and mycelium grown on media in which flavonoids were used as supplements, yet flavonoids were not detected because they could not absorb them.

\section{Conclusion}

Based on the World Health Food Rating, the fruiting bodies of all the samples of Pleurotus ostreatus investigated in this study presented excellent rating in nutrient density for zinc, manganese, copper, magnesium, iron, fibre, potassium, sodium, calcium, thiamine, vitamin $\mathrm{B}_{2}$ and niacinamide. The results therefore reveal that substrate organic supplementation techniques could improve the nutrient density of Pleurotus ostreatus. However, the process had no observable effect on the flavonoid composition of the samples. 


\section{References}

i. Alicia, G., Cristina, P., Esther, B. \& Cristina, S. (2015). Mushrooms do not contain flavonoids. Indian Journal of Functional Foods 2(5): 1-13.

ii. Barros, L., Correia, D. M., Ferreira, I. C. F. R., Baptista, P. \& Santos - Buelga, C. (2008). "Optimization of the Determination of tocopherols in Agaricins sp. Edible mushrooms by a normal phase liquid chromatographic method". Food chemistry 110(4), 1046-1050.

iii. Guggenhelm, A. G., Wright, K. M. \& Zwickey, H. L. (2014). Immune modulationfrom five major mushroom: application to integrative oncology. Integrative medicine and chemical mushrooms: role in the prevention of cardiovascular diseases, Fitoterapia, 81, (7), .715-723.

iv. Hall, I. R. (2010). "Growing mushroom: the commercial reality". Lifestyle farmer. Aukland, New Zealand: Rural press: 42-45. Retrieved 26, January, 2012.

v. Hossian, S., Hashimoto, M., Choudhury, E. K., Alam, N., Hussam, S., Hasan, M., Choudhury, S. K., \& Mahmud, I. (2003). Dietary mushroom (pleurotusostreatus) ameliorates atherogenic lipid on hypercholesterolaemic rats. Clinical and experimental pharmacology and physiology; 30: 470-475.

vi. Maria, E. V., Talia, \& O'ctavio, P. (2014). Edible Mushroom: Improving Human Health and Promoting Quality life.International Journal of Microbiology,2015, (D 376387), 14.

vii. Mathla, P., Salo-Vaanane, P., Konko, K., Aro, H., \& Talava, T. (2002). "Basic composition and amino acid contents of mushrooms cultivated in finland". Journal of Agriculture food chemistry, 50,6419-6422.

viii. $\quad$ Mishra, K. K., Pal, R. S., Arunkumar, R., Chandrashekara, C., Jain, S. K., \& Bhatt, J. C. (2013). "Antioxidant properties of different edible mushroom species and increased bioconversion efficiency of pleurotus eryngii using locallyavailable casing materials". 1557-1563.

ix. Mshigeni, K. E., \& Chang, S. T. (2000). A guide to successful mushroom farmingan agenda for developing Africa differently. University of Namibia, 41.

x. Teeney, M. J. et al., (2014). Mushrooms and Health Summit procedures. Journal of Nutrition 144(7). 11285-11365

xi. Vaz, J. A., Heleno, S. A., Martins, A., Almeida, G. M., Vasconcelos, M. A. \& Ferreira, I. C. F. R. (2010). "Wild mushrooms Clitocybe alexandri and lepsitainversa: in vitro antioxidant activity and growth inhibition of human tumor cell lines, food and chemical toxicology, 48, (10), 2381-2884.

xii. Zu, Y. G., Fu, Y. J., Liu, W., Hou, C. L. \& Kong, Y. (2006). Simultaneous determination of four flavonoids in pigeon pea cajanus cajan (L.) Millsp. Leaves using RP-LC-DAD Chromatographia, 63(9): 499-505.

xiii. Guillamon, E., Garcia-Lafuente, A., Lozano, M. et al., (2010) Edible mushrooms: Role in the prevention of cardiovascular diseases.Filoterapia,81(7):715-723

xiv. Adejumo, T.O. and Awosanya, O.B. (2005) Proximate and mineral composition of four edible mushroom species from South-Western Nigeria. AfricanJournal ofBiotechnology;4(10):1084-1088.

xv. Nakalembe, I., Kabasa, J.D., and Olila, D. (2015). Comparative nutrient composition of selected wild edible mushrooms from two agro-ecological zones, Uganda; Springplus ,4(1):433

xvi. FAO(1972). Food Composition Table for use in East Asia. FAO Rome: FoodPolicy, Food Nutritional Division. [Google Scholar].

xvii. Food andNutrition Board. Institute of Medicine (2001). Dietary reference intake for vitamin A, Vitamin K, arsenic, boron, chromium, copper, iodine, iron, manganese, molybdenum, nickel, silicon, vanadium and zink. Washington, D.C. National Academies, National Academies Press.

xviii. Kabasa, J.D., Olila, D., Okethwangu, D., Munishi, P.K.T., Kisovi, L. (2006). Nutritive and nutriceutic potential of Indigenous Bubaala mushroom, Termitomyces microcarpus from the Lake Victoria Basin. African Journal of Animal Biomedical Science; 1(1):92-96[Google Scholar]

xix. Beltran-Garcia, Miguel,J., Estarron, E., and Mirna, O.T.(1997).Volatile compounds secreted by the oyster mushroom(P.ostreatus) and their anti-bacterial activities. Journal Agricultural and Food Chemistry,45(10):4049.

xx. Drewnowski, A.(2005) Concept of nutritious food: toward a nutrient density score. American Journal of Clinical Nutrition; 82:721-32

xxi. Kuo, N. (2005). Pleurotus ostreatus: The oyster mushroom. Retrieved from the mushroom expert. Come website: http:// ww.mushroomexpart.com/ pleurotusostreatus.html 